Research Article

\title{
Cross-Efficiency Evaluation under Probabilistic Hesitant Fuzzy Environment and Its Application to the Portfolio Selection Process
}

\author{
Yutong Zhang $\mathbb{D}^{1},{ }^{1}$ Wei Zhou $\mathbb{D}^{1},{ }^{1}$ Danxue Luo $\mathbb{D},{ }^{1}$ and Xiaorong $\mathrm{He} \mathbb{D}^{2}$ \\ ${ }^{1}$ Business School, Yunnan University of Finance and Economics, Kunming 650221, China \\ ${ }^{2}$ School of Information Engineering, Nanjing Audit University, Nanjing, Jiangsu 211815, China \\ Correspondence should be addressed to Danxue Luo; 1034159312@qq.com
}

Received 16 September 2021; Accepted 5 November 2021; Published 26 November 2021

Academic Editor: Ali Ahmadian

Copyright ( 2021 Yutong Zhang et al. This is an open access article distributed under the Creative Commons Attribution License, which permits unrestricted use, distribution, and reproduction in any medium, provided the original work is properly cited.

In the case of insufficient quantitative data, qualitative evaluation information is very important for investment decision-making. However, if it is completely based on qualitative evaluation information, the results may be subjective. In response to this problem, this paper proposes a method, namely, probabilistic hesitant fuzzy cross-efficiency evaluation (PHFCEE) method, based on probabilistic hesitant fuzzy theory, cross-efficiency data envelopment analysis (CEDEA). This method uses probabilistic hesitant fuzzy sets to collect qualitative evaluation information and then uses the cross-efficiency DEA model to fuse quantitative data and qualitative information. And finally, an investment portfolio is built based on the cross-efficiency value and its variance. In addition, this article gives the specific operating steps of the PHFCEE method and uses the construction of a portfolio of 10 stocks in the China CSI 300 Index as an example to illustrate the effectiveness of this method.

\section{Introduction}

The investment portfolio can effectively diversify risks [1]. At present, a large number of suitable tools and sophisticated models have been used for portfolio construction and selection research [2]. However, most of the methods that have been constructed require sufficient quantitative data [3, 4]. In fact, in the research process, there are situations where important indicators are difficult to quantify, there is no data, or there is little data $[5,6]$. For example, the level of the team is difficult to measure with quantitative data, and the company that has just gone public has no financial data, etc. In addition, quantitative data are almost all historical data, which has certain limitations and one-sidedness in reflecting expected information and uncertain information. Based on the consideration of the above issues, we constructed the PHFCEE model and apply it to portfolio selection. We use expert evaluation to measure some qualitative indicators and then use CEDEA to fuse quantitative data and expert evaluation information and finally build an investment portfolio based on cross-efficiency values and constraints. This article will use probability fuzzy theory to describe the expert's evaluation information. It is an interesting method to combine qualitative evaluation with quantitative data to construct a portfolio. Because experts have knowledge, experience, wisdom, and thinking and judgment capabilities that far exceed those of ordinary investors, they can grasp the essence and key points from complex information and give a more objective evaluation. The quantitative data can effectively reflect historical information and further ensure the objectivity of the model results.

At present, according to the type and quantity of data required by the model, the research of portfolio model can be roughly divided into the following three categories: First, a portfolio model that requires a large amount of time-series data to calculate statistical indices. Representative methods are Markowitz's portfolio model and its extended models, such as Huang [7], Zhao and Xiao [8], and Kuzmanovic et al. [9]. Second, the investment portfolio model proposed is based on the nonstatistical model, which requires relatively little data. Nonstatistical methods used in portfolio models include neural networks [10], CEDEA [11], genetic algorithms [12], and fuzzy theory [13, 14]. Third, some qualitative portfolio models were developed based on fuzzy 
environments, such as Wang and Zhu [15], Chiarawongse et al. [16], and Zhou and Xu [3, 4].

However, fuzzy data is usually used to describe uncertain information provided by experts, investors, or decisionmakers $[17,18]$, which is subjective. Therefore, we believe that integrating some quantitative data into the model can build a more effective investment portfolio. Fuzzy theory is widely used in various fields because it can describe uncertain information. In the field of investment, interval fuzzy sets [19-21], hesitant fuzzy sets [22, 23], intuitionistic fuzzy sets [24, 25], and probabilistic hesitant fuzzy sets $[18,26]$ are often used to describe all kinds of evaluation information. These documents provide a theoretical basis for this article to describe qualitative information using fuzzy theory. Taking into account the inconsistent preferences of the expert group when making complex multiattribute decision-making, this paper chooses to use probabilistic hesitant fuzzy sets to describe the evaluation information of the expert group.

In addition, there are differences between the evaluation information of experts and the measurement methods of quantitative data. Therefore, it is necessary to find a model to fuse the two kinds of information. Sexton et al. [27] proposed a CEDEA model that can consider both self-evaluation and mutual evaluation, which provides an effective method for this paper to evaluate efficiency using data covering both quantitative and qualitative information. The CEDEA model has the characteristics of dimensionless, and it is also a method of measuring the overall organizational efficiency on multiple metrics and synthesizing a single index. These characteristics provide a theoretical basis for the fusion of data in this paper. In addition, the CEDEA model has been applied to portfolio evaluation or selection $[11,28,29]$. These articles provide a valuable reference for us to use the calculation results of cross-efficiency DEA to construct investment portfolios.

Based on the above background and literature review, this paper will combine probabilistic hesitant fuzzy theory, CEDEA model, and mean-variance to construct a new portfolio method. Its main function is to construct a portfolio based on quantitative data and qualitative evaluation information. As an illustration of the methodology presented in this article, we report a case study involving 10 companies in the China CSI 300 Index. In addition, the possible advantages of this article are as follow: First, the model uses both quantitative data and qualitative evaluation to describe important information about investment products or projects, which will show product features more comprehensively. This will help decision-makers or investors to make more accurate judgments. Second, the model uses the cross-efficiency DEA model to fuse two forms of data. Third, the model can be used for portfolio construction with only one data form or mixed data information form.

The rest of this article is structured as follows: Section 2 introduces the basic knowledge of hesitant fuzzy, probabilistic hesitant fuzzy, and CEDEA model. In Section 3, we build a method, named PHFCEE model, and introduce the steps to use it for portfolio selection. Section 4 provides a practical case to demonstrate the effectiveness and operability of this model. Section 5 introduces the conclusions, shortcomings, and prospects of this article.

\section{Preliminary Concepts}

As an effective multicriteria decision-making method, the cross-efficiency DEA is often used in portfolio selection and construction. But when using this method, it is mostly based on objective statistical data, and the statistical data has certain one-sidedness and limitations. In order to overcome this shortcoming, this paper introduces the probabilistic hesitant fuzzy data with subjective information into the CEDEA model to form a new method of portfolio construction based on comprehensive information. This part will briefly introduce the basic theories and concepts involved in the new method, that is, hesitant fuzzy, probabilistic hesitant fuzzy, and the CEDEA model.

\subsection{Hesitant Fuzzy Set (HFS) and Probabilistic Hesitant Fuzzy} Set (PHFS). To solve the problem of inconsistent preferences of experts in complex multiattribute decision-making, Torra [30, 31] proposed the hesitant fuzzy set, whose core idea is that all the preferences of experts are taken as membership values. This concept is expressed as follows:

Definition 1 (see $[30,31]$ ). Given any nonempty set $S$, the hesitant fuzzy set $H(s)$ defined in the collection $S$ can be expressed as

$$
H(s)=\{<s, h(s)>\mid s \in S\},
$$

where $h(s)=\left(\gamma^{\tau} \mid \tau=1,2, \cdots, \ell\right), s$ is an element in the set $S, h(s)$ is the hesitant fuzzy element, $\gamma \in[0,1]$ is the degree of membership, and arranged in ascending order, and $\tau$ represents the sort position of $\gamma \cdot H(s)$ is the set of $h(s)$, and $h(s)$ is the set of $\gamma$.

Example 1. If an expert's rating on the return on assets of an enterprise is 0.5 or 0.6 , the corresponding hesitant fuzzy element can be expressed as $h(s)=\{0.5,0.6\}$.

According to Definition 1 and Example 1, all membership degrees in HFS have the same importance or the same probability. However, when evaluating assets, it is usually carried out by multiple experts, and experts have a certain tendency to score. Example 2. If the expert's score for a certain company's return on assets is more inclined to 0.6 , this means that the degree of membership of 0.6 is more important or the probability of occurrence is greater. Example 3. Suppose that the set of scores given by Expert 1 and Expert 2 on the return on assets of a certain enterprise are $\{0.5,0.6\}$ and $\{0.6,0.7\}$, respectively. Then, the hesitant fuzzy element composed of the comprehensive information of Expert 1 and Expert 2 is denoted as $h(s)=\{0.5,0.6,0.7\}$. Among them, 0.6 appears in both score sets, indicating that it has a more important degree.

From the above analysis, it can be seen that the degree of membership in the HFS, that is, the expert score, fails to reflect the tendency of the expert score and the number of experts. This will result in the loss of a large amount of 
decision-making information. Therefore, this paper further uses PHFS to synthesize the evaluation information of the expert group. This concept can be expressed as follows.

Definition 2 (see [32]). Given any nonempty set $S$, the probabilistic hesitant fuzzy set $\dot{H}(s)$ defined on set $S$ can be expressed as

$$
\dot{H}(s)=\{<s, h(p(s))>\mid s \in S\},
$$

where $h(p(s))=\left(\gamma^{\tau}\left|p^{\tau}\right| \tau=1,2, \cdots \ell\right), s$ is an element in the set $S, h(p(s))$ is the hesitant probabilistic fuzzy element, $\gamma \in[0,1]$ is the degree of membership arranged in ascending order, and $\tau$ represents the sort position of $\gamma$. When $p^{\tau}=c, c=1 / \ell(\tau=1,2, \cdots \ell)$, the probabilistic hesitant fuzzy set $\dot{H}(s)$ degenerates into the hesitant fuzzy set $H(s)$.

Example 4. Based on Example 3, the probabilistic hesitant fuzzy element can be expressed as $h(p(s))=\{0.5|0.25,0.6| 0.5,0.7 \mid 0.25\}$, where the membership degrees are $0.5,0.6$, and 0.7 , respectively. The probability of 0.5 is 0.25 , the probability of 0.6 is 0.5 , and the probability of 0.7 is 0.25 . It is found that the probability of 0.6 is higher than other membership degrees.

2.2. Cross-Efficiency DEA Model (CEDEA). CEDEA can not only effectively measure efficiency, but also provides a method to systematically choose a weight when there are multiple metrics. All these provide the basis for this article to build a portfolio based on objective data and subjective judgments. The calculation steps of the CEDEA model are briefly described as follows [27].

Suppose that there are as many as $l$ DMUs whose efficiency needs to be measured, denoted as $\mathrm{DMU}_{r},(r=1,2, \cdots, l)$; each DMU evaluated hasm kinds of inputs and $n$ kinds of outputs, denoted as $x_{i}(i=1,2, \cdots, m)$ and $y_{j}(j=1,2, \cdots, n)$, respectively; the weights of inputs and outputs are $\alpha_{i}(i=1,2, \cdots, m)$ and $\beta_{j}(j=1,2, \cdots, n)$, respectively.

First, solve the efficiency value $e_{t t}$ of $\mathrm{DMU}_{t}$ based on the linear programming form of the CCR model [33]:

$$
\begin{aligned}
& e_{t t}= \operatorname{Max} \sum_{j=1}^{n} \beta_{j} y_{j t}, \\
& \text { s.t. }\left\{\begin{array}{l}
\sum_{j=1}^{n} \beta_{j} y_{j t}-\sum_{j=1}^{n} \alpha_{i} x_{i r} \leq 0, \\
\sum_{i=1}^{m} \alpha_{i} x_{i t}=1, \\
\alpha_{i} \geq 0, \beta_{j} \geq 0, \\
i=1,2, \cdots, m, j=1,2, \cdots, n, t, r=1,2, \cdots, l,
\end{array}\right.
\end{aligned}
$$

where $e_{t t}$ is the efficiency value of $\mathrm{DMU}_{t}$ and $x_{i t}, x_{i r}$ are the $m$ kinds of inputs of $\mathrm{DMU}_{t}$ and $\mathrm{DMU}_{r}$, respectively, and $y_{j t}$, $y_{j r}$ are the $n$ outputs of $\mathrm{DMU}_{t}$ and $\mathrm{DMU}_{r}$, respectively, $\alpha_{i}$ and $\beta_{j}$ are the weights of input and output, respectively, $t, r=1,2, \cdots, l, i=1,2, \cdots, m$ and $j=1,2, \cdots, n$.

Second, the optimal weights $\alpha_{i t}^{*}$ and $\beta_{j t}^{*}$ of $\mathrm{DMU}_{t}$ calculated in model (3) are substituted into the following equation to calculate the mutual evaluation efficiency value $e_{t r}$ between $\mathrm{DMU}_{t}$ and $\mathrm{DMU}_{r}$ :

$$
e_{t r}=\frac{\sum_{j=1}^{n} \beta_{j t}^{*} y_{j r}}{\sum_{i=1}^{m} \alpha_{i t}^{*} x_{i r}}, \quad t, r=1,2, \ldots, l ; t \neq r .
$$

Third, to calculate the cross-efficiency value $\bar{e}_{r}$ of $\mathrm{DMU}_{r}$, the formula is as follows:

$$
\bar{e}_{r}=\frac{1}{l} \sum_{t=1}^{l} e_{t r}=\frac{1}{l} \sum_{t=1}^{l} \frac{\sum_{j=1}^{n} \beta_{j t}^{*} y_{j r}}{\sum_{i=1}^{m} \alpha_{i t}^{*} x_{i r}} .
$$

In addition, calculate the degree of deviation of cross efficiency of $\mathrm{DMU}_{r}$, that is, the variance. The formula is as follows:

$$
\sigma_{r}^{2}=\frac{1}{l} \sum_{t=1}^{l}\left(e_{t r}-\bar{e}_{r}\right)^{2}
$$

This section briefly introduces the definitions of hesitant fuzzy set and probabilistic hesitant fuzzy set and the application steps of the CEDEA model. This provides a theoretical basis for constructing the PHFCEE method.

\section{PHFCEE Model Construction and Portfolio Selection}

At present, portfolio selection and efficiency evaluation are mostly based on objective statistical data, ignoring the onesidedness and limitations of statistical data. However, the probabilistic hesitant fuzzy theory can effectively deal with the fuzzy subjective evaluation information of experts. Therefore, this paper introduces it into the CEDEA model and puts forward the PHFCEE model. The essence of the model is to take the multiangle and multifactor fuzzy evaluation data of the expert group as the output or input in the CEDEA model at the same time. Then, the portfolio is constructed based on the efficiency value and its variance, which is estimated by the PHFCEE model.

In the whole method, first of all, each expert evaluates the attributes of the asset to form a hesitant fuzzy set, and then based on all the hesitant fuzzy sets obtained by the expert group, a comprehensive hesitant fuzzy set is formed. Finally, the probabilistic hesitant fuzzy set is formed by calculating the probability. Definitions 4-6 are proposed to show more clearly how the model integrates information and obtains the probability of membership. The relevant definitions are as follows.

Definition 4. Given that $S$ is a nonempty set. The comprehensive hesitant fuzzy set $\widetilde{H}$ defined on set $S$ can be expressed as

$$
\widetilde{H}=\left\{<s, h^{\prime}(s)>\mid s \in S\right\},
$$


where $\quad h^{\prime}(s)\left(h^{\prime}(s)=\left\{{ }^{1} h(s) \cup{ }^{2} h(s) \cup \cdots \cup{ }^{k} h(s)\right\} \quad\right.$ is the comprehensive hesitant fuzzy element and ${ }^{k} h(s)$ represents a hesitant fuzzy element.

Definition 5. Given any comprehensive hesitant fuzzy element $h^{\prime}(s)=\left(\gamma^{\tau} \mid \tau=1,2, \cdots \ell\right)$, let $h^{\prime}=h^{\prime}(s)$, where membership degrees can be defined as follows:

$$
\begin{aligned}
& \gamma^{\tau^{\prime}} \in\left\{\gamma_{1}^{\tau_{1}} \cup \gamma_{2}^{\tau_{2}} \cup \cdots \cup \gamma_{k}^{\tau_{k}}\right\}, \\
& \sum_{a=1}^{k} \tau_{a} \geq \ell^{\prime} \geq \ell\left(\tau_{a}=1,2, \cdots \ell ; a=1,2, \cdots k\right) .
\end{aligned}
$$

where $\gamma^{\tau^{\prime}}$ is membership degrees of the comprehensive hesitant fuzzy element, $\gamma_{k}^{\tau_{k}}$ corresponds to the hesitant fuzzy element of the $k$ th expert, $\tau_{a}, \tau^{\prime}$ is the ranking of the membership degree, which is sorted by default from small to large, and $\ell, \ell^{\prime}$ are the number of membership degree and comprehensive membership degree, respectively.

Definition 6. Given an arbitrary probabilistic hesitant fuzzy element $h(p(s))=\left(\gamma^{\tau}\left|p^{\tau}\right| \tau=1,2, \cdots \ell\right)$, let $\widetilde{h^{\prime}}=h(p(s))$ such that the probability corresponding to its membership degree can be defined as

$$
p^{\tau^{\prime}}=\frac{N\left(\gamma^{\tau^{\prime}}\right)}{\sum_{a=1}^{k} \tau_{a}},
$$

where $N\left(\gamma^{\tau^{\prime}}\right)$ represents the frequency of the same membership value $s$ in the $k$ hesitant fuzzy elements of the attribute and $\sum_{a=1}^{k} \tau_{a}$ represents the sum of the number of all the subhesitant fuzzy elements.

Because the CEDEA model cannot effectively deal with the fuzzy data of probabilistic hesitant degree, this paper obtains its expected value based on probability to represent the expert group's score of asset attributes. Above, the $S$ nonempty collection defined represents the property collection of the asset.

Definition 7. Given an arbitrary probabilistic hesitant fuzzy element $h(p(s))=\left(\gamma^{\tau^{\prime}}\left|p^{\tau^{\prime}}\right| t \tau^{\prime} n=q 1,2 h, \ldots x \ell^{\prime}\right)$, the score function is defined as

$$
E\left(\widetilde{h^{\prime}}\right)=\sum_{\tau=1}^{\ell} \gamma^{\tau^{\prime}} p^{\tau^{\prime}}
$$

Definition 8. Given any nonempty set $Y$, defining the corresponding set $Y$ of scores on the sets $(s \in S)$, it can be expressed as

$$
Y=\left\{<s, E\left(\widetilde{h^{\prime}}\right)>\mid s \in S\right\}
$$

Then, the score set of all assets can be represented by a matrix, and at the same time, $y^{\prime}=E\left(\widetilde{h^{\prime}}\right)$ :

$$
\left[\begin{array}{cccc}
s_{11} & s_{12} & \cdots & s_{1 b} \\
s_{21} & s_{22} & \cdots & s_{2 b} \\
\vdots & \vdots & \cdots & \vdots \\
s_{l 1} & s_{l 2} & \cdots & s_{l b}
\end{array}\right]\left[\begin{array}{cccc}
y_{11}^{\prime} & y_{12}^{\prime} & \cdots & y_{1 n^{\prime \prime}}^{\prime} \\
y_{21}^{\prime} & y_{22}^{\prime} & \cdots & y_{2 n^{\prime \prime}}^{\prime} \\
\vdots & \vdots & \cdots & \vdots \\
y_{l 1}^{\prime} & y_{l 2}^{\prime} & \cdots & y_{l n^{\prime \prime}}^{\prime}
\end{array}\right],
$$

where it corresponds $s_{l b}$ to $y_{l b}$ one by one. $s_{l b}$ represents the $l$ attribute of the $b$ asset; then $y_{l b}^{\prime}$ corresponds to the comprehensive score given by the expert group.

Secondly, based on the above definition and formula, the PHFCEE method containing probabilistic fuzzy information data is constructed, and its linear programming form is as follows:

$$
\begin{aligned}
& e_{t t}^{*}=\operatorname{Max} \sum_{j=1}^{n^{\prime}} \beta_{j} y_{j t}+\sum_{b=1}^{n^{\prime \prime}} \beta_{b} y_{b t}^{\prime}, \\
& \text { s.t. }\left\{\begin{array}{l}
\sum_{j=1}^{n^{\prime}} \beta_{j} y_{j t}+\sum_{b=1}^{n^{\prime \prime}} \beta_{b} y_{b t}^{\prime}-\sum_{i=1}^{m} \alpha_{i} x_{i r} \leq 0, \\
\sum_{i=1}^{m} \alpha_{i} x_{i t}=1, \\
\alpha_{i} \geq 0, \beta_{j} \geq 0, \beta_{b} \geq 0
\end{array}\right.
\end{aligned}
$$

where $e_{t t}^{*}$ is the optimal efficiency value of the $t$ asset $\left(\mathrm{DMU}_{t}\right), x_{i t}$ and $x_{i r}$ have $m$ kinds of inputs of assets, $y_{j t}$ and $y_{j r}$ have $n^{\prime}$ kinds of the objective statistical data output of assets, $y_{b t}, y_{b r}$ are $n^{\prime \prime}$ kinds of the subjective fuzzy data output of assets, $\alpha_{i}$ is input weights, and $\beta_{j}$ and $\beta_{b}$ are output weights.

Through model (13), the optimal efficiency value $e_{t t}^{*}$ and the corresponding optimal weights $\alpha_{i t}^{*}, \beta_{j t}^{*}, \beta_{b t}^{*} \mathrm{DMU}_{t}$ are obtained, and the mutual evaluation efficiency $\dot{e}_{t r}$ of $\mathrm{DMU}_{r}$, as shown in Table 1, is further calculated.

$$
\dot{e}_{t r}=\frac{\sum_{j=1}^{n^{\prime}} \beta_{j t}^{*} y_{j r}+\sum_{b=1}^{n^{\prime \prime}} \beta_{b t}^{*} y_{b r}^{\prime}}{\sum_{i=1}^{m} \alpha_{i t}^{*} x_{i r}}, \quad t, r=1,2, \cdots, l ; t \neq r .
$$

The cross-efficiency $\tilde{\bar{e}}_{r}$ of $\mathrm{DMU}_{r}$ and its variance $\tilde{\sigma}_{r}^{2}$ are calculated as follows: 


$$
\begin{aligned}
& \widetilde{\bar{e}}_{r}=\frac{1}{l} \sum_{t=1}^{l} e_{t r}=\frac{1}{l} \sum_{t=1}^{l} \frac{\sum_{j=1}^{n^{\prime}} \beta_{j t}^{*} y_{j r}+\sum_{b=1}^{n^{\prime \prime}} \beta_{b t}^{*} y_{b r}^{\prime}}{\sum_{i=1}^{m} \alpha_{i t}^{*} x_{i r}}, \\
& \widetilde{\sigma}_{r}^{2}=\frac{1}{l} \sum_{t=1}^{l}\left(\dot{e}_{t r}-\widetilde{\bar{e}}_{r}\right)^{2} .
\end{aligned}
$$

Finally, the cross-efficiency value $\widetilde{\bar{e}}_{r}$ and its variance $\widetilde{\sigma}_{r}^{2}$ are defined as the return and risk of financial assets, respectively [11]. Based on the mean-variance framework, a portfolio selection method including probability model information and cross efficiency can be established. We provide the portfolio selection method of maximizing return and the portfolio selection method of minimizing risk, as follows.

The revenue maximization under constraint conditions:

$$
\begin{aligned}
& e^{\#}=\max \sum_{r=1}^{l} w_{r} \widetilde{\bar{e}}_{r} \\
& \text { s.t }\left\{\sum_{r=1}^{l} w_{r} \overline{\bar{e}}_{r} \geq \frac{1}{l} \sum_{r=1}^{l} \widetilde{\bar{e}}_{r}, \sum_{r=1}^{l} w_{r}^{2} \widetilde{\sigma}_{r}^{2} \leq \frac{1}{l^{2}} \sum_{r=1}^{l} \widetilde{\sigma}_{r}^{2}, \sum_{r=1}^{l} w_{r}=1, w_{r} \geq 0, r=1,2, \cdots, l .\right.
\end{aligned}
$$

Risk minimization under constraints:

$$
\begin{aligned}
& e^{\diamond}=\min \sum_{r=1}^{l} w_{r}^{2} \widetilde{\sigma}_{r}^{2} \\
& \text { s.t }\left\{\sum_{r=1}^{l} w_{r} \widetilde{\bar{e}}_{r} \geq \frac{1}{l} \sum_{r=1}^{l} \widetilde{\bar{e}}_{r}, \sum_{r=1}^{l} w_{r}^{2} \widetilde{\sigma}_{r}^{2} \leq \frac{1}{l^{2}} \sum_{r=1}^{l} \widetilde{\sigma}_{r}^{2}, \sum_{r=1}^{l} w_{r}=1, w_{r} \geq 0, r=1,2, \cdots, l,\right.
\end{aligned}
$$

where $w_{r}$ is the weight of the $\mathrm{DMU}_{r}$, that is, the investment proportion of the corresponding financial assets; $l$ is the number of assets; the purpose function is to maximize the return $e^{\#}$ and minimize the market risk $e^{\diamond}$; the constraint conditions mean that the expected return of the portfolio should not be lower than the average return, and the risk should not be higher than the average risk, so the sum of the investment proportion of the assets is 1 .

To better illustrate the operability and practicability of the above method, this paper gives specific steps. Suppose there are as many as $l$ decision-making units $\left(\mathrm{DMU}_{r}\right.$, $r=1,2, \cdots, l)$, among which there are $m$ inputs $\left(x_{i}\right.$, $i=1,2, \cdots, m)$, and there are $n^{\prime}$ objective outputs $\left(y_{j}\right.$, $\left.j=1,2, \cdots, n^{\prime}\right)$ and $n^{\prime \prime}$ subjective fuzzy inputs $\left(y_{b}^{\prime}\right.$, $\left.b=1,2, \cdots, n^{\prime \prime}\right)$. At the same time, fuzzy input corresponds to the comprehensive evaluation of attributes of the $n^{\prime \prime}$ decision-making units by the expert group $(G)$, in which the attributes are $\left(s_{b}, b=1,2, \cdots, n^{\prime \prime}\right), k$ members of the expert group $\left(G_{a}, a=1,2, \cdots, k\right)$, the comprehensive score is $\left(E_{b}\left(\# h^{\prime}\right), b=1,2, \cdots n^{\prime \prime}\right)$, the hesitant fuzzy set is $H_{k}$, the comprehensive hesitant fuzzy set is $\widetilde{H}$, and the probabilistic hesitant module set $\dot{H}$. (i) The first step is to obtain the hesitant fuzzy set of all attributes of the decision-making unit from the members of the expert group.

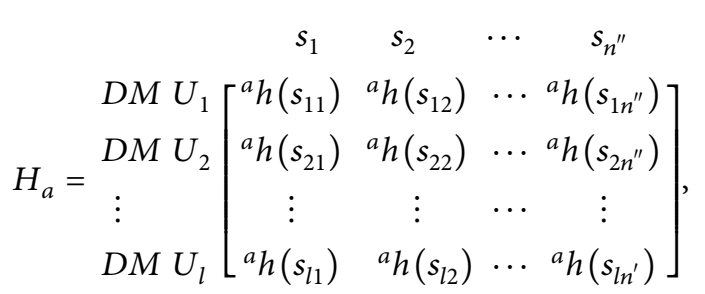

where $^{a} h\left(s_{r b}\right)=\left(\gamma_{l n^{\prime \prime}}^{\tau_{a}} \mid \tau_{a}=1,2, \cdots u ; a\right.$ $\left.=1,2, \cdots k ; r=1,2, \cdots, l ; b=1,2, \cdots, n^{\prime \prime}\right)$.

(ii) the second step, according to Definition 4 and Definition 5, the hesitant fuzzy set $H_{a}(a=1,2, \cdots k)$ of the expert members is combined to form a comprehensive hesitant fuzzy set $\widetilde{H}$ for all attributes of all decision-making units. And then, 


$$
\begin{aligned}
& h^{\prime}(s)=\left\{{ }^{1} h(s) \cup{ }^{2} h(s) \cup \cdots \cup^{k} h(s)\right\},
\end{aligned}
$$

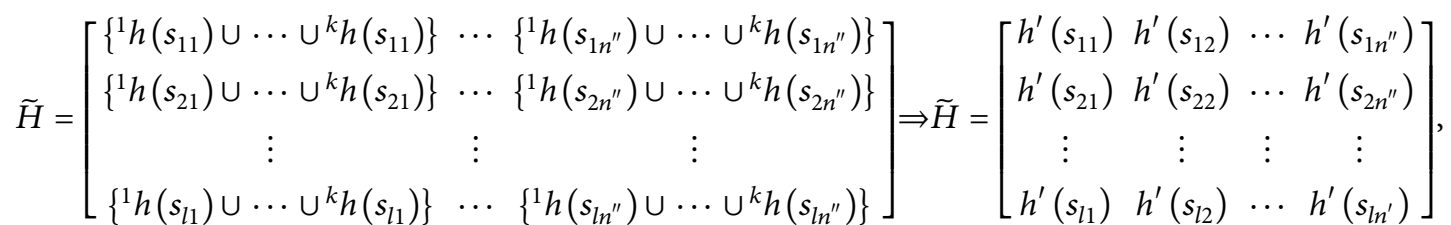

whereh $^{\prime}\left(s_{r b}\right) \quad=\left(\gamma^{\tau} \mid \tau=1,2, \cdots, \ell ; r\right.$ $\left.=1,2, \cdots, l ; b=1,2, \cdots, n^{\prime \prime}\right)$.

(iii) The third step is to calculate the probability of the membership degree in the comprehensive hesitant fuzzy element according to Definition 6, that is, equation (10), to form a probabilistic hesitant fuzzy set $\dot{H}$ as follows:

$$
\dot{H}=\left[\begin{array}{cccc}
h\left(p\left(s_{11}\right)\right) & h\left(p\left(s_{12}\right)\right) & \cdots & h\left(p\left(s_{1 n^{\prime \prime}}\right)\right) \\
h\left(p\left(s_{21}\right)\right) & h\left(p\left(s_{22}\right)\right) & \cdots & h\left(p\left(s_{2 n^{\prime \prime}}\right)\right) \\
\vdots & \vdots & \vdots & \vdots \\
h\left(p\left(s_{l 1}\right)\right) & h\left(p\left(s_{l 2}\right)\right) & \cdots & h\left(p\left(s_{l n^{\prime \prime}}\right)\right)
\end{array}\right]=\left[\begin{array}{ccc}
\left\{\gamma_{11}^{1}\left|p_{11}^{1}, \cdots, \gamma_{11}^{\ell}\right| p_{11}^{\ell}\right\} & \cdots & \left\{\gamma_{1 n^{\prime \prime}}^{1}\left|p_{1 n^{\prime \prime}}^{1}, \cdots, \gamma_{1 n^{\prime \prime}}^{\ell}\right| p_{1 n^{\prime \prime}}^{1}\right\} \\
\left\{\gamma_{21}^{1}\left|p_{21}^{1}, \cdots, \gamma_{21}^{\ell}\right| p_{21}^{\ell}\right\} & \cdots & \left\{\gamma_{2 n^{\prime \prime}}^{1}\left|p_{2 n^{\prime \prime}}^{1}, \cdots, \gamma_{2 n^{\prime \prime}}^{\ell}\right| p_{2 n^{\prime \prime}}^{1}\right\} \\
\vdots & \vdots & \vdots \\
\left\{\gamma_{l 1}^{1}\left|p_{l 1}^{1}, \cdots, \gamma_{l 1}^{\ell}\right| p_{l 1}^{\ell}\right\} & \cdots & \left\{\gamma_{l n^{\prime \prime}}^{1}\left|p_{l n^{\prime \prime}}^{1}, \cdots, \gamma_{l n^{\prime \prime}}^{\ell}\right| p_{l n^{\prime \prime}}^{1}\right\}
\end{array}\right]
$$

(iv) In the fourth step, according to Definition 7 and Definition 8, the probabilistic hesitant fuzzy set $\dot{H}$ is calculated, and the comprehensive evaluation information of the expert group is obtained, which is shown as follows:

$$
E(\dot{H})=\left[\begin{array}{cccc}
E\left(\# h_{11}^{\prime}\right) & E\left(\# h_{12}^{\prime}\right) & \cdots & E\left(\# h_{1 n^{\prime \prime}}^{\prime}\right) \\
E\left(\# h_{21}^{\prime}\right) & E\left(\# h_{22}^{\prime}\right) & \cdots & E\left(\# h_{2 n^{\prime \prime}}^{\prime}\right) \\
\vdots & \vdots & \vdots & \vdots \\
E\left(\# h_{l 1}^{\prime}\right) & E\left(\# h_{l 2}^{\prime}\right) & \cdots & E\left(\# h_{l n^{\prime \prime}}^{\prime}\right.
\end{array}\right] \Rightarrow Y=\left[\begin{array}{cccc}
y_{11}^{\prime} & y_{12}^{\prime} & \cdots & y_{1 n^{\prime \prime}}^{\prime} \\
y_{21}^{\prime} & y_{22}^{\prime} & \cdots & y_{2 n^{\prime \prime}}^{\prime} \\
\vdots & \vdots & \vdots & \vdots \\
y_{l 1}^{\prime} & y_{l 2}^{\prime} & \cdots & y_{l n^{\prime \prime}}^{\prime}
\end{array}\right],
$$

where $\quad y_{r b}^{\prime}=E\left(\# h_{r b}^{\prime}\right),(r=1,2, \cdots, l ; b=1,2, \cdots$, $\left.n^{\prime \prime}\right)$.

(v) In the fifth step, $x_{i}, \quad y_{j}$, $y_{b}^{\prime}\left(i=1,2, \cdots, m ; r=1,2, \cdots, l ; b=1,2, \cdots, n^{\prime \prime}\right)$ is substituted into model (12) to estimate the optimal efficiency value $\operatorname{DMU}_{t}(t=1,2, \cdots, l)$ of the evaluated asset $e_{t t}^{*}$ and its corresponding optimal weight $\alpha_{i t}^{*}, \beta_{j t}^{*}, \beta_{b t}^{*}$.

(vi) In the sixth step, the optimal weight of $\mathrm{DMU}_{t}(t=1,2, \cdots, l)$ is substituted into equation (13) to calculate the mutual evaluation efficiency of $\dot{e}_{t r}(r \neq t)$, as shown in Table 1 .

(vii) In the seventh step, the crossover efficiency values $\widetilde{\bar{e}}_{r}$ and variance $\widetilde{\sigma}_{r}^{2}$ are calculated according to equations (14) and (15), as shown in Table 2.

(viii) In the eighth step, the cross-efficiency value $\widetilde{\bar{e}}_{r}$ and variance $\widetilde{\sigma}_{r}^{2}$ estimated by the cross-efficiency DEA are defined as the return and risk of the investment, respectively, and then the investment weight is calculated based on the investor's investment purpose model (16) or (17). Model (16) maximizes the profit and model (7) minimizes the risk.

\section{Illustrated Example}

Investors often build their portfolios based on quantitative data and information and lack of adoption and analysis of qualitative information. The main reason is that qualitative information is difficult to quantify. To solve this problem, the method of expert evaluation is introduced to evaluate the attribute information that cannot be quantified, and the fuzzy methods of hesitant and probabilistic hesitant are used to collect and quantify the evaluation information with preference. To fuse and analyze the quantitative data and qualitative information, this paper further introduces the CEDEA model, which has the advantage of dimensionless. Based on this, this paper proposes the PHFCEE model to measure the cross-efficiency (benefit) and variance (risk) containing quantitative and qualitative information. Finally, 
TABle 1: Mutual evaluation efficiency matrix among decision-making units.

\begin{tabular}{ccccc}
\hline Assets & $\mathrm{DMU}_{1}$ & $\mathrm{DMU}_{2}$ & $\cdots$ & \\
\hline $\mathrm{DMU}_{1}$ & $\dot{e}_{11}$ & $\dot{e}_{12}$ & $\cdots$ & $\mathrm{DMU}_{l}$ \\
$\mathrm{DMU}_{2}$ & $\dot{e}_{21}$ & $\dot{e}_{22}$ & $\cdots$ & \\
$\vdots$ & $\vdots$ & $\vdots$ & $\cdots$ & $\dot{e}_{1 l}$ \\
$\mathrm{DMU}_{l}$ & $\dot{e}_{l 1}$ & $\dot{e}_{l 2}$ & $\ldots$ & $\vdots$ \\
\hline
\end{tabular}

Note. The diagonal is the self-evaluation efficiency of the asset; the nondiagonal element is the mutual evaluation efficiency between the assets.

TABLE 2: Cross efficiency and variance.

\begin{tabular}{lcccc}
\hline Assets & $\mathrm{DMU}_{1}$ & $\mathrm{DMU}_{2}$ & $\cdots$ & $\mathrm{DMU}_{l}$ \\
\hline $\bar{e}_{r}$ & $\widetilde{\bar{e}}_{1}$ & $\widetilde{\bar{e}}_{2}$ & $\cdots$ & $\widetilde{\bar{e}}_{l}$ \\
$\tilde{\sigma}_{r}^{2}$ & $\widetilde{\sigma}_{1}^{2}$ & $\widetilde{\sigma}_{2}^{2}$ & $\ldots$ & $\widetilde{\sigma}_{l}^{2}$ \\
\hline
\end{tabular}

the calculation results of the PHFCEE model are substituted into the portfolio model constructed in the third part to calculate the final portfolio components and weights.

To demonstrate the effectiveness of the method proposed in this paper, we select 10 stocks in the CSI 300 index for a case study. The corresponding enterprises (code/variable life) are Industrial and Commercial Bank of China (601398/ DMU1), China Pacific Insurance (601601/DMU2), Shanghai Pharmaceutical (601607/DMU3), China Zhongzhi (601618/ DMU4), China Life Insurance (601628/DMU5), China Construction (601668/DMU6), Shanghai Electric (601727/ DMU7), Everbright Securities (601788/DMU8), China Exemption (601888/DMU9), and Zijin Mining (601899/ DMU10). In addition, because the general CEDEA model cannot deal with data with negative values, this paper excludes enterprises with missing values and negative values when screening sample data. Finally, the ten enterprises shown above are formed as samples. According to the annual report of the enterprise in 2020, the relevant financial data are obtained to calculate the input and output indicators required by the PHFCEE model. Indicators that will reflect the operational ability, solvency, and growth ability of the enterprise $[11,34,35]$ are considered as input to the PHFCEE model. The profitability of the enterprise and the market reaction of the stock is taken as the output of the objective data of the model. In addition, this paper also takes the output of the subjective data of the model through the evaluation of experts from the aspects of enterprise prospect, enterprise innovation, team level, and so on. Specific information on the relevant indicators is shown in Table 3.

In Table 3, except for the expert evaluation section, the corresponding financial data in other sectors can be calculated from the annual report data published by enterprises between March and April each year. This paper takes the annual report data of 10 enterprises in 2020 as an example. The expert evaluation section consists of a team of three experts to evaluate the selected enterprises from three aspects: enterprise prospect, enterprise innovation, and team level, in which the evaluation result of each expert is expressed in the form of the hesitant fuzzy set. The evaluation result of the expert group is expressed by the comprehensive hesitant fuzzy set, and the evaluation result of the expert group considering the importance of membership is expressed by the probabilistic hesitant fuzzy set. According to the specific steps of the method given in the third part of the article, the analysis of this case is as follows.

The first step is to obtain the evaluation results of 10 enterprises by three experts from three aspects: enterprise prospect, enterprise innovation, and team level, using hesitant fuzzy set $H_{1}, H_{2}$, and $H_{3}$ Express. The correspondence is shown in Tables 4-6, respectively. The second step, based on Definitions 4 and 5, merges the hesitant fuzzy elements for the same attribute in the hesitation fuzzy set and of the three experts and finally combines the comprehensive hesitation fuzzy set, which contains the evaluation results of all attributes of 10 enterprises, as shown in Table 7.

The third step is to calculate the probability of each membership degree in the comprehensive hesitant fuzzy set according to equation (10), to form a probabilistic hesitant fuzzy set $\dot{H}$ that contains more expert group evaluation information, as shown in Table 8.

The fourth step is based on Definitions 7 and 8 and probabilistic hesitant fuzzy set $\dot{H}$. The comprehensive scores for each attribute of 10 enterprises are calculated, respectively, and the results are shown in Table 9.

In the fifth step, the input and output data of 10 enterprises are substituted into model (12) to estimate the optimal self-evaluation efficiency value $e_{t t}^{*}$ and the optimal weight $\alpha_{i t}^{*}$, $\beta_{j t}^{*}, \beta_{b t}^{*}$, and substitute it into model (13) to calculate the mutual evaluation efficiency between enterprises $\dot{e}_{t r}(r \neq t)$. The estimated results run through MATLAB are shown in Table 10. In this table, the value on the diagonal is the selfevaluation efficiency of the enterprise, and the nondiagonal data of each row is the mutual evaluation efficiency of other enterprises to the corresponding enterprises of the bank.

The sixth step is to calculate the cross-efficiency value $\tilde{\bar{e}}_{r}$ and variance $\widetilde{\sigma}_{r}^{2}$ between enterprises according to equation (15) and equation (16) and sort them from large to small, as shown in Table 11.

According to Table 11, the three enterprises with the largest cross-efficiency values are DMU1, DMU5, and DMU2, and their corresponding variances are 0.2031 (10), 0.3457 (4), and 0.3428 (5), respectively. Thus, it can be seen that except for the relatively high return and relatively low risk of enterprise DMU1, the income and risk of other enterprises show different characteristics.

In the seventh step, the cross-efficiency value $\tilde{\bar{e}}_{r}$ and variance $\widetilde{\sigma}_{r}^{2}$ are regarded as the risk and return of the investment, respectively, and substituted into model (17) or model (18) to calculate the investment weight $w$. It is assumed that there are no taxes, no transaction costs, no short selling, and full liquidity when constructing the investment portfolio. 
TABle 3: Details of input and output metrics.

\begin{tabular}{lccc}
\hline Types & Aspect & Financial indicators or evaluation indicators & Variable abbreviation \\
\hline \multirow{3}{*}{ Input } & Operation ability & Asset turnover rate & $x_{1}$ \\
& Debt paying ability & Asset-liability ratio & $x_{2}$ \\
$x_{3}$ & $y_{1}$ \\
\hline \multirow{3}{*}{ Output } & Growth ability & Income growth rate & $y_{2}$ \\
& Profitability & Net profit margin & $y_{3}$ \\
& Stock & Stock price & $y_{4}$ \\
\hline
\end{tabular}

TABLE 4: Results of Expert 1 assessment.

\begin{tabular}{lccr}
\hline Enterprises & $s_{1}$ & $s_{2}$ & $s_{3}$ \\
\hline DMU1 & $(0.5,0.6)$ & $(0.3,0.4)$ & $(0.5,0.6)$ \\
DMU2 & $(0.6,0.7)$ & $(0.6)$ & $(0.4,0.5,0.6)$ \\
DMU3 & $(0.6,0.7)$ & $(0.4)$ & $(0.5)$ \\
DMU4 & $(0.7,0.8)$ & $(0.6,0.7)$ & $(0.5,0.7)$ \\
DMU5 & $(0.6,0.7)$ & $(0.5,0.6)$ & $(0.4,0.6)$ \\
DMU6 & $(0.6,0.75)$ & $(0.4)$ & $(0.4,0.3)$ \\
DMU7 & $(0.4,0.5)$ & $(0.3)$ & $(0.4)$ \\
DMU8 & $(0.55)$ & $(0.5,0.6)$ & $(0.4,0.50)$ \\
DMU9 & $(0.7)$ & $(0.4,0.5)$ & $(0.5)$ \\
DMU10 & $(0.4,0.5)$ & $(0.5,0.4)$ & $0.45)$ \\
\hline
\end{tabular}

TABLE 5: Results of Expert 2 assessment.

\begin{tabular}{lccc}
\hline Enterprises & $s_{1}$ & $s_{2}$ & $s_{3}$ \\
\hline DMU1 & $(0.3,0.5)$ & $(0.6,0.9)$ & $(0.4,0.6,0.8)$ \\
DMU2 & $(0.4,0.6,0.7)$ & $(0.2,0.6)$ & $(0.3,0.7)$ \\
DMU3 & $(0.4,0.5)$ & $(0.5,0.8)$ & $(0.4,0.5)$ \\
DMU4 & $(0.7,0.8)$ & $(0.5,0.6,0.7)$ & $(0.2,0.4)$ \\
DMU5 & $(0.4,0.7)$ & $(0.5)$ & $(0.5,0.8)$ \\
DMU6 & $(0.65)$ & $(0.5,0.6)$ & $(0.6)$ \\
DMU7 & $(0.3,0.5)$ & $(0.6,0.7)$ & $(0.45,0.7)$ \\
DMU8 & $(0.6,0.75)$ & $(0.3,0.65)$ & $(0.55)$ \\
DMU9 & $(0.4,0.6)$ & $(0.4)$ & $(0.65)$ \\
DMU10 & $(0.5)$ & $(0.4,0.85)$ \\
\hline
\end{tabular}

TABLE 6: Results of Expert 3 assessment.

\begin{tabular}{lccc}
\hline Enterprises & $s_{1}$ & $s_{2}$ & $s_{3}$ \\
\hline DMU1 & $(0.5,0.6)$ & $(0.3)$ & $(0.4,0.6,0.7)$ \\
DMU2 & $(0.3)$ & $(0.6,0.8)$ & $(0.5)$ \\
DMU3 & $(0.5,0.7)$ & $(0.4)$ & $(0.6)$ \\
DMU4 & $(0.5,0.6)$ & $(0.7)$ & $(0.4,0.6)$ \\
DMU5 & $(0.4,0.5)$ & $(0.6)$ & $(0.5,0.55)$ \\
DMU6 & $(0.45,0.7)$ & $(0.55,0.5)$ & $(0.4,0.65)$ \\
DMU7 & $(0.3,0.4,0.65)$ & $(0.6)$ & $(0.4,0.7)$ \\
DMU8 & $(0.3)$ & $(0.35)$ & $(0.4)$ \\
DMU9 & $(0.4)$ & $(0.4)$ & $(0.5,0.75)$ \\
DMU10 & $(0.45)$ & $(0.6)$ & $(0.4)$ \\
\hline
\end{tabular}

In this paper, $5,6,7$, and 8 enterprises with high crossefficiency are selected to construct the investment portfolio, and the investment weights under different constraints are obtained, as shown in Tables 12 and 13. From the observation, we can see something important. First, with the increase of the number of stocks in the portfolio, the weight of the corresponding stocks of each enterprise is decreasing accordingly. Second, no matter how many stocks are included in the investment portfolio, whether the purpose of the portfolio construction is to maximize the return or 
TABLE 7: Comprehensive evaluation results of the expert group.

\begin{tabular}{lccr}
\hline Enterprises & $s_{1}$ & $s_{2}$ & $s_{3}$ \\
\hline DMU1 & $(0.3,0.5,0.6)$ & $(0.3,0.4,0.6,0.9)$ & $(0.4,0.5,0.6,0.7,0.8)$ \\
DMU2 & $(0.3,0.4,0.6,0.7)$ & $(0.2,0.6,0.8)$ & $(0.3,0.4,0.5,0.6,0.7)$ \\
DMU3 & $(0.4,0.5,0.6,0.7)$ & $(0.4,0.5,0.8)$ & $(0.4,0.5,0.6)$ \\
DMU4 & $(0.5,0.6,0.7,0.8)$ & $(0.5,0.6,0.7)$ & $(0.2,0.4,0.5,0.6,0.7)$ \\
DMU5 & $(0.4,0.5,0.6,0.7)$ & $(0.5,0.6)$ & $(0.4,0.5,0.55,0.6,0.8)$ \\
DMU6 & $(0.3,0.5,0.6,0.65,0.75)$ & $(0.3,0.5,0.6)$ & $(0.3,0.4,0.6,0.65)$ \\
DMU7 & $(0.3,0.4,0.5,0.65)$ & $(0.4,0.45,0.55,0.6,0.8)$ & $(0.4,0.45,0.7)$ \\
DMU8 & $(0.3,0.55,0.6,0.75)$ & $(0.35,0.6,0.65)$ & $(0.4,0.50,0.55)$ \\
DMU9 & $(0.4,0.6,0.7)$ & $(0.4,0.6,0.7)$ & $(0.5,0.65,0.75)$ \\
DMU10 & $(0.4,0.45,0.5)$ & & $(0.4,0.5,0.6,0.85)$ \\
\hline
\end{tabular}

TABLE 8: Results of comprehensive evaluation of Expert groups with preferences $(\dot{H})$.

\begin{tabular}{lccc}
\hline Enterprises & $s_{1}$ & $s_{2}$ & $s_{3}$ \\
\hline DMU1 & $(0.3|0.17,0.5| 0.5,0.6 \mid 0.33)$ & $(0.3|0.4,0.4| 0.2,0.6|0.2,0.9| 0.2)$ & $(0.4|0.25,0.5| 0.375,0.6|0.125,0.7| 0.125,0.8 \mid$ \\
& $(0.3|0.17,0.4| 0.17,0.6|0.33,0.7| 0.33)$ & $(0.2|0.2,0.6| 0.6,0.8 \mid 0.2)$ & $(0.3|0.17,0.4| 0.17,0.5|0.34,0.6| 0.17,0.7 \mid 0.17)$ \\
DMU2 & $(0.4|0.17,0.5| 0.33,0.6|0.17,0.7| 0.33)$ & $(0.4|0.5,0.5| 0.25,0.8 \mid 0.25)$ & $(0.4|0.25,0.5| 0.5,0.6 \mid 0.25)$ \\
DMU3 & $(0.5|0.17,0.6| 0.17,0.7|0.33,0.8| 0.33)$ & $(0.5|0.17,0.6| 0.33,0.7 \mid 0.5)$ & $(0.2|0.17,0.4| 0.34,0.5|0.17,0.6| 0.17,0.7 \mid 0.17)$ \\
DMU4 & $(0.4|0.33,0.5| 0.17,0.6|0.17,0.7| 0.33)$ & $(0.5|0.5,0.6| 0.5)$ & $(0.4|0.17,0.5| 0.34,0.55|0.17,0.6| 0.17,0.8 \mid$ \\
DMU5 & $(0.3|0.2,0.5| 0.2,0.6|0.2,0.65| 0.2,0.75 \mid$ & $(0.3|0.4,0.5| 0.4,0.6 \mid 0.2)$ & $0.17)$ \\
DMU6 & $0.2)$ & $(0.3|0.2,0.4| 0.4,0.6|0.2,0.65| 0.2)$ \\
DMU7 & $(0.3|0.29,0.4| 0.29,0.5|0.29,0.65| 0.14)$ & $(0.4|0.2,0.45| 0.2,0.55|0.2,0.6| 0.2,0.8 \mid$ & $(0.4|0.5,0.45| 0.25,0.7 \mid 0.25)$ \\
DMU8 & $(0.3|0.25,0.55| 0.25,0.6|0.25,0.75|$ & $0.2)$ & $(0.4|0.5,0.50| 0.25,0.55 \mid 0.25)$ \\
DMU9 & $(0.4|0.5,0.6| 0.25,0.7 \mid 0.25)$ & $(0.35|0.25,0.5| 0.25,0.6|0.25,0.7| 0.25)$ & $(0.5|0.5,0.65| 0.25,0.75 \mid 0.25)$ \\
DMU10 & $(0.4|0.25,0.45| 0.25,0.5 \mid 0.5)$ & $(0.4|0.75,0.5| 0.25)$ & $(0.4|0.4,0.5| 0.2,0.6|0.2,0.85| 0.2)$ \\
\hline
\end{tabular}

TABLE 9: The comprehensive score of each attribute of 10 enterprises.

\begin{tabular}{lccc}
\hline Enterprises & $s_{1}$ & $s_{2}$ & $s_{3}$ \\
\hline DMU1 & 0.50 & 0.5 & 0.55 \\
DMU2 & 0.47 & 0.56 & 0.51 \\
DMU3 & 0.53 & 0.525 & 0.5 \\
DMU4 & 0.61 & 0.633 & 0.476 \\
DMU5 & 0.51 & 0.55 & 0.5695 \\
DMU6 & 0.56 & 0.32 & 0.47 \\
DMU7 & 0.44 & 0.56 & 0.4875 \\
DMU8 & 0.55 & 0.4625 & 0.4625 \\
DMU9 & 0.53 & 0.5375 & 0.6 \\
DMU10 & 0.46 & 0.425 & 0.55 \\
\hline
\end{tabular}

minimize the risk, the investment weight of the enterprise DMU1 is the largest. Third, under the condition of income maximization, the investment right of DMU1 is more important than the investment weight of risk minimization.

Combined with the analysis of Tables 11 and 12, when investors aim to maximize returns, each portfolio will increase the investment weight of stocks with higher returns on the premise of not exceeding the average risk. Similarly, combined with the analysis of Tables 11 and 13, when investors aim to minimize risk, each investment portfolio will increase the investment weight of less risky stocks on the premise that the return is not lower than the average return. The above results are consistent with the facts, which shows the rationality of the portfolio construction model.
In addition, the return and risk of the portfolio are calculated according to the required weight and compared with the return and risk of the equal weight investment; the results are shown in Table 14. The analysis shows that the investment weight calculated based on model (16) and model (17) is lower than the equal weight investment in terms of return and risk. The investment return of income maximization is higher than that of risk minimization, and the risk of risk minimization is lower than that of return maximization. The comparison results in Table 14 are in line with expectations, which once again illustrates the rationality and effectiveness of the portfolio construction in this paper.

Compared with the quantitative portfolio selection methods such as modern portfolio theory [36-38], the 
TABLe 10: Table of efficiency values among 10 enterprises.

\begin{tabular}{lcccccccccc}
\hline & DMU1 & DMU2 & DMU3 & DMU4 & DMU5 & DMU6 & DMU7 & DMU8 & DMU9 & DMU10 \\
\hline DMU1 & 1.0000 & 0.9638 & 0.6461 & 0.6414 & 0.9851 & 1.0000 & 0.6650 & 0.7968 & 0.4023 & 0.7068 \\
DMU2 & 0.0273 & 1.0000 & 0.2707 & 0.6739 & 0.9719 & 0.8599 & 0.4330 & 0.4024 & 0.1481 & 0.6817 \\
DMU3 & 0.0026 & 0.7010 & 1.0000 & 0.7823 & 0.7675 & 1.0000 & 0.1046 & 0.1231 & 0.0667 & 0.3541 \\
DMU4 & 0.0033 & 0.9315 & 0.1510 & 1.0000 & 0.9513 & 1.0000 & 0.1949 & 0.2170 & 0.0642 & 0.4431 \\
DMU5 & 0.0349 & 0.9592 & 0.2608 & 0.7115 & 1.0000 & 0.9156 & 0.4894 & 0.4971 & 0.1499 & 0.7432 \\
DMU6 & 0.0068 & 0.4896 & 0.1281 & 0.5017 & 0.5548 & 0.9710 & 0.1065 & 0.2148 & 0.1264 & 0.4592 \\
DMU7 & 0.0071 & 0.5451 & 0.0326 & 0.5156 & 0.7367 & 0.5156 & 1.0000 & 0.7148 & 0.1163 & 0.5809 \\
DMU8 & 0.0401 & 0.4958 & 0.0442 & 0.5193 & 0.6546 & 0.6872 & 0.7149 & 1.0000 & 0.4085 & 0.5764 \\
DMU9 & 0.0221 & 0.3701 & 0.0227 & 0.3975 & 0.6199 & 0.4619 & 0.3385 & 0.3840 & 1.0000 & 0.5624 \\
DMU10 & 0.0340 & 0.6866 & 0.0748 & 0.7118 & 0.9283 & 0.8379 & 0.3749 & 0.4561 & 0.2667 & 1.0000 \\
\hline
\end{tabular}

TABLE 11: Cross efficiency (benefit), variance (risk), and ranking.

\begin{tabular}{lcccc}
\hline Enterprises & $\tilde{\bar{e}}_{r}$ & Sort & $\tilde{\sigma}_{r}^{2}$ & Sort \\
\hline DMU1 & 0.7807 & 1 & 0.2031 & 0.3428 \\
DMU2 & 0.5469 & 3 & 0.4008 & \\
DMU3 & 0.4902 & 7 & 0.4249 & \\
DMU4 & 0.4956 & 6 & 0.3457 & \\
DMU5 & 0.5762 & 2 & 0.2937 & \\
DMU6 & 0.3559 & 10 & 0.3273 & 8 \\
DMU7 & 0.4765 & 8 & 0.2957 & 6 \\
DMU8 & 0.5141 & 5 & 0.2839 & 7 \\
DMU9 & 0.4179 & 9 & 0.3470 & 9 \\
DMU10 & 0.5371 & 4 & & 3 \\
\hline
\end{tabular}

TABLE 12: Investment weight of income maximization.

\begin{tabular}{lccccccc}
\hline Enterprises & $w$ & Enterprises & $w$ & Enterprises & $w$ & Enterprises & $w$ \\
\hline DMU1 & 0.3671 & DMU1 & 0.3427 & DMU1 & 0.3099 & DMU1 & 0.2723 \\
DMU2 & 0.1541 & DMU2 & 0.1364 & DMU2 & 0.1238 & DMU2 & 0.1119 \\
DMU5 & 0.1607 & DMU5 & 0.1435 & DMU5 & 0.1301 & DMU5 & 0.1171 \\
DMU10 & 0.1497 & DMU10 & 0.1320 & DMU10 & 0.1198 & DMU10 & 0.1085 \\
DMU8 & 0.1684 & DMU8 & 0.1472 & DMU8 & 0.1337 & DMU8 & 0.1217 \\
- & - & DMU4 & 0.0982 & DMU4 & 0.0892 & DMU4 & 0.0815 \\
- & - & - & - & DMU3 & 0.0934 & DMU3 & 0.0854 \\
- & - & - & - & - & - & DMU7 & 0.1016 \\
\hline
\end{tabular}

TABLE 13: Risk-minimized portfolio weight.

\begin{tabular}{lccccccc}
\hline Enterprises & $w$ & Enterprises & $w$ & Enterprises & $w$ & Enterprises & $w$ \\
\hline DMU1 & 0.2897 & DMU1 & 0.2545 & DMU1 & 0.2254 & DMU1 & 0.1977 \\
DMU2 & 0.1716 & DMU2 & 0.1508 & DMU2 & 0.1335 & DMU2 \\
DMU5 & 0.1702 & DMU5 & 0.1495 & DMU5 & 0.1324 & DMU5 & 0.1172 \\
DMU10 & 0.1696 & DMU10 & 0.1489 & DMU10 & 0.1319 & DMU10 \\
DMU8 & 0.1990 & DMU8 & 0.1748 & DMU8 & 0.1548 & 0.1157 \\
- & - & DMU4 & 0.1216 & DMU4 & 0.1077 & DMU8 & 0.1358 \\
- & - & - & - & DMU3 & 0.1142 & DMU3 & 0.0945 \\
- & - & - & - & - & - & 0.1002 \\
\hline
\end{tabular}

PHFCEE model proposed in this paper uses more comprehensive information, and then the derived results meet the real needs of investors and companies because this model not only uses quantitative data reflecting historical information but also uses hesitant fuzzy sets to describe some qualitative factors that cannot be measured with quantitative data. Compared with the qualitative portfolio model proposed by Zhou and Xu [3,4] and others, the given model also uses some quantitative financial data to ensure the objectivity of the given results. The incomplete rationality of experts could lead to subjectivity in the evaluation information provided by experts and decision-makers, which can 
TABLE 14: Comparison of income and risk.

\begin{tabular}{lccccc}
\hline Amount & $\begin{array}{c}\text { The average } \\
\text { return on } \\
\text { investment }\end{array}$ & $\begin{array}{c}\text { Weighted return under } \\
\text { income maximization }\end{array}$ & $\begin{array}{c}\text { Weighted return } \\
\text { under risk } \\
\text { minimization }\end{array}$ & $\begin{array}{c}\text { The average } \\
\text { investment in risk }\end{array}$ & $\begin{array}{c}\text { Weighted risk under } \\
\text { profit maximization } \\
\text { risk } \\
\text { under risk } \\
\text { minimization }\end{array}$ \\
\hline 5 & 0.59100 & 0.63046 & 0.61143 & 0.06058 & 0.06016 \\
6 & 0.57511 & 0.62008 & 0.59735 & 0.05387 & 0.05356 \\
7 & 0.56298 & 0.60773 & 0.58511 & 0.04776 & 0.04748 \\
8 & 0.55216 & 0.59277 & 0.57178 & 0.04168 & 0.04145 \\
\hline
\end{tabular}

further affect the optimal results. Then, we add objective quantitative data into the model. Concerning these comparisons, the investment portfolio derived by this model could be more realistic and reasonable than that got by the other two types of models.

\section{Conclusions}

A portfolio approach that utilizes qualitative information is an effective venture capital technique when quantitative data are scarce or unavailable. However, the approach of building a portfolio using only qualitative information is somewhat subjective. To solve this problem, this paper proposes the PHFCEE model. The acquisition of qualitative information and the effective fusion of two data forms are the key technologies for portfolio construction. Then, we introduce probabilistic hesitant fuzzy set and the CEDEA model. Next, based on the cross-efficiency value and its variance, the investment portfolio ratios considering the investors' risk preferences are constructed. Lastly, a real example has been provided to demonstrate the feasibility of the proposed models.

The mixed-data portfolio model based on the probabilistic hesitant fuzzy environment in this paper has some disadvantages, such as simple modeling rules, simple probabilistic calculation, and excessively ideal constraints. Therefore, in future work, the research will further consider the mixed-data portfolio model under the environment with incomplete or no-probability information and intend to develop a new probability solution algorithm. It will be worthwhile and interesting work.

\section{Data Availability}

The data used to support the findings of this study are available from the corresponding author upon request.

\section{Conflicts of Interest}

The authors declare that they have no conflicts of interest regarding the publication of this paper.

\section{Acknowledgments}

This work was supported by the Natural Science Foundation of China (nos. 72071176 and 71840001), the Humanities and Social Sciences in Universities of Jiangsu Province, China (no. 2019SJA0337), and the Natural Science Research Project of Universities in Jiangsu Province, China (no. 19KJB120008).

\section{References}

[1] X. Zhou, J. Wang, and X. Yang, "Portfolio selection under different attitudes in fuzzy environment," Information Sciences, vol. 462, pp. 278-289, 2018.

[2] S. Guo, L. Yu, and X. Li, "Fuzzy multi-period portfolio selection with different investment horizons," European Journal of Operational Research, vol. 254, no. 3, pp. 1026-1035, 2016.

[3] W. Zhou and Z. S. Xu, "Portfolio selection and risk investment under the hesitant fuzzy environment," Knowledge-Based Systems, vol. 144, pp. 21-31, 2018.

[4] W. Zhou and Z. S. Xu, "Hesitant fuzzy linguistic portfolio model with variable risk appetite and its application in the investment ratio calculation," Applied Soft Computing, vol. 84, Article ID 105719, 2019.

[5] L. Dimova, P. Sevastianov, and D. Sevastianov, "MCDM in a fuzzy setting: investment projects assessment application," International Journal of Production Economics, vol. 100, no. 1, pp. 10-29, 2006.

[6] P. Hildebrandt and T. Knoke, "Investment decisions under uncertainty-a methodological review on forest science studies," Forest Policy and Economics, vol. 13, no. 1, pp. 1-15, 2011.

[7] X. X. Huang, "A new perspective for optimal portfolio selection with random fuzzy returns," Information Science, vol. 177, pp. 5404-5414, 2007.

[8] P. Zhao and Q. Xiao, "Portfolio selection problem with valueat-risk constraints under non-extensive statistical mechanics," Journal of Computational and Applied Mathematics, vol. 298, pp. 64-71, 2016.

[9] M. Kuzmanovic, D. Makajic-Nikolic, and N. Nikolic, "Preference based portfolio for private investors: discrete choice analysis approach," Mathematics, vol. 8, no. 1, p. 30, 2020.

[10] A. Fernandez and S. Gomez, "Portfolio selection using neural networks," Computers and Operations Research, vol. 34, no. 1, pp. 1177-1191, 2005.

[11] S. Lim, K. W. Oh, and J. Zhu, "Use of DEA cross-efficiency evaluation in portfolio selection: an application to Korean stock market," European Journal of Operational Research, vol. 236, no. 1, pp. 361-368, 2014.

[12] P. Sinha, A. Chandwani, and T. Sinha, "Algorithm of construction of optimum portfolio of stocks using genetic algorithm," International Journal of Systems Assurance Engineering and Management, vol. 6, pp. 35-44, 2015.

[13] Y. J. Liu and W. G. Zhang, "Fuzzy portfolio selection model with real features and different decision behaviors," Fuzzy Optimization and Decision Making, vol. 17, pp. 317-336, 2018.

[14] B. Wang, Y. Li, S. M. Wang, and J. Watada, "A multi-objective portfolio selection model with fuzzy value-at-risk ratio," IEEE Transactions on Fuzzy Systems, vol. 26, pp. 3673-3687, 2018. 
[15] S. Wang and S. Zhu, "On fuzzy portfolio selection problems," Fuzzy Optimization and Decision Making, vol. 1, pp. 361-377, 2002.

[16] A. Chiarawongse, S. Kiatsupaibul, S. Tirapat, and B. V. Roy, "Portfolio selection with qualitative input," Journal of Banking \& Finance, vol. 36, no. 2, pp. 489-496, 2012.

[17] M. W. Lin, Y. Q. Chen, and R. Q. Chen, "Bibliometric analysis on Pythagorean fuzzy sets during 2013-2020," International Journal of Intelligent Computing and Cybernetics, vol. 14, no. 2, pp. 104-121, 2021.

[18] M. Liu, C. H. Zhang, and C. H. Yu, "Knowledge diffusion trajectories in the Pythagorean fuzzy field based on main path analysis," International Journal of Intelligent Computing and Cybernetics, 2021.

[19] L. T. Zhou, Y. F. Wang, and Y. Jiang, "Investment project assessment by a MAGDM method based on the ranking of interval type-2 fuzzy sets," Journal of Intelligent and Fuzzy Systems, vol. 35, no. 2, pp. 1875-1888, 2018.

[20] A. Serguieva and J. Hunter, "Fuzzy interval methods in investment risk appraisal," Fuzzy Sets and Systems, vol. 142, no. 3, pp. 443-466, 2004.

[21] X. Q. Xu, J. L. Xie, and Y. Na, "Probabilistic uncertain linguistic TODIM method based on the generalized Choquet integral and its application," International Journal of Intelligent Computing and Cybernetics, vol. 14, no. 2, pp. 122-144, 2021.

[22] S. Yang and Y. Ju, "A GRA method for investment alternative selection under Dual hesitant fuzzy environment with incomplete weight information," Journal of Intelligent and Fuzzy Systems, vol. 28, no. 4, pp. 1533-1543, 2015.

[23] P. Zhou, J. Luo, and F. Cheng, "Analysis of risk priorities for renewable energy investment projects using a hybrid IT2 hesitant fuzzy decision-making approach with alpha cuts," Energy, vol. 4, Article ID 120184, 2021.

[24] L. Wang and J. Pu, "Research on the investment performance evaluation of corporate venture capital with intuitionistic fuzzy information," Journal of Intelligent \& Fuzzy Systems: Applications in Engineering and Technology, vol. 30, no. 3, pp. 1783-1790, 2016.

[25] M. Zhao, G. Wei, and C. Wei, "Improved TODIM method for intuitionistic fuzzy MAGDM based on cumulative prospect theory and its application on stock investment selection," International Journal of Machine Learning and Cybernetics, vol. 12, pp. 891-901, 2020.

[26] W. Y. Wu, Z. W. Ni, and F. F. Jin, "Investment selection based on Bonferroni mean under generalized probabilistic hesitant fuzzy environments," Mathematics, vol. 9, p. 107, 2021.

[27] T. R. Sexton, R. H. Silkman, and A. J. Hogan, "Data envelopment analysis: critique and extensions," New Directions for Evaluation, vol. 32, pp. 73-105, 1986.

[28] H. Essid, J. Ganouati, and S. Vigeant, "A mean-maverick game cross-efficiency approach to portfolio selection: an application to Paris stock exchange," Expert Systems with Applications, vol. 113, pp. 161-185, 2018.

[29] Z. Mashayekhi and H. Omrani, "An integrated multi-objective Markowitz-DEA cross-efficiency model with fuzzy returns for portfolio selection problem," Applied Soft Computing, vol. 38, pp. 1-9, 2016.

[30] V. Torra, "Hesitant fuzzy sets," International Journal of Intelligent Systems, vol. 25, no. 6, pp. 529-539, 2010.

[31] V. Torra and Y. Narukawa, "On hesitant fuzzy sets and decision," in Proceedings of the 18th IEEE International Conference on Fuzzy Systems, pp. 1378-1382, IEEE, Jeju Island, Korea, August 2009.
[32] Z. S. Xu and W. Zhou, "Consensus building with a group of decision makers under the hesitant probabilistic fuzzy environment," Fuzzy Optimization and Decision Making, vol. 16, no. 4, pp. 481-503, 2017.

[33] A. Charnes, W. W. Cooper, and E. Rhodes, "Measuring the efficiency of decision making units," European Journal of Operational Research, vol. 2, no. 6, pp. 429-444, 1978.

[34] N. C. P. Edirisinghe and X. Zhang, "Generalized DEA model of fundamental analysis and its application to portfolio optimization," Journal of Banking \& Finance, vol. 31, no. 11, pp. 3311-3335, 2007.

[35] N. C. P. Edirisinghe and X. Zhang, "Portfolio selection under DEA-based relative financial strength indicators: case of US industries," Journal of the Operational Research Society, vol. 59, no. 6, pp. 842-856, 2008.

[36] J. B. Clempner and A. S. Poznyak, "Sparse mean-variance customer Markowitz portfolio optimization for Markov chains: a Tikhonov's regularization penalty approach," Optimization and Engineering, vol. 19, no. 2, pp. 383-417, 2018.

[37] L. G. Hong, S. Juneja, and G. W. Liu, "Kernel smoothing for nested estimation with application to portfolio risk measurement," Operations Research, vol. 65, no. 3, pp. 657-673, 2017.

[38] H. M. Markowitz, "Portfolio selection, journal of finance," vol. 7, pp. 77-91, 1952. 